\title{
Method Development and Validation for Simultaneous Estimation of Dexlansoprazole and Meloxicam by Rp-Hplc
}

Jalli Sriharsha*, Srinivasa Murthy M, Bharat Kumar D, Sravan K, Shiva kumar P, Shirisha A and Pranusha K

Vignan Institute of Pharmaceutical Sciences, Deshmukhi, Nalgonda

\begin{abstract}
To develop a method for simultaneous estimation of Dexlansoprazole and Meloxicam by RP-HPLC and validate the developed method according to $\mathrm{ICH}$ guidelines. The column used for method development of Dexlansoprazole and Meloxicam was Hypersil-BDS, C18, 250*4.6 mm, $5 \mu$. Methanol and Acetonitrile were used in the ration of 60:40 for the method development. The developed method was validated for various parameters such as specificity, linearity, range, accuracy, precision, system suitability, robustness, ruggedness etc. The method was developed and optimized method was chosen and validated and the results were tabulated according to ICH guidelines. The result obtained in this study demonstrated that the HPLC method described is specific, accurate, precise, linear, ruggedness, robustness and stability indicating for the simultaneous determination of Dexlansoprazole and Meloxicam.
\end{abstract}

Keywords: Meloxicam; Dexlansoprazole; HPLC

\section{Introduction}

Method validation can be defined as (ICH) Establishing documented evidence, which provides a high degree of assurance that a specific activity will consistently produce a desired result or product meeting its predetermined specifications and quality characteristics [1-7]. Method validation study include system suitability, linearity, precision, accuracy, specificity, robustness, limit of detection, limit of quantification and stability of samples, reagents, instruments.

\section{System suitability}

Before starting any experiment, the operator should daily check the functioning of the HPLC so as to be sure that the system is capable of providing results of high accuracy [8].

\section{Linearity}

Linearity is defined as the measure of the proximity of the straight line obtained from a calibration plot of response vs. concentration. It can be obtained by performing the experiments using different concentrations of the analyte [9].

\section{Precision}

Precision is the degree of similarity between individual results when the same test procedure is applied to different samplings of a same sample [10].

\section{Accuracy}

The accuracy is the closeness of an obtained value to the true value. A method with high accuracy, the measured value is identical to the true value [11].

\section{Specificity/Selectivity}

According to $\mathrm{ICH}$, the term specific indicates a method producing results for a single analyte while the term selective indicates a method producing results for a number of analytes [12].

\section{Robustness}

According to ICH robustness is a measure of the capacity of a method to remain unaffected by small, variations in parameters used in the method.

\section{Limit of detection}

LOD is the least concentration of an analyte in a sample that can be detected, but not quantified using specific experimental conditions [13].

\section{Limit of quantification}

LOQ is the least concentration of an analyte that can be detected with preferable precision and accuracy using specific experimental conditions.

\section{Materials and Methods}

\section{Instruments}

HPLC-Waters 2690/5 with PDA Detector, Software-Empower Electronic balance-Mettler Toledo Model XS-205DU

Sonicator (FAST CLEAN)

\section{Column details}

Hypersil-BDS, C18, 250^4.6 mm, $5 \mu$

\section{Reagents}

Purified water (Milli-Q)

Methanol HPLC Grade

Acetonitrile

Raw material

Dexlansoprazole and Meloxicam working Standards

*Corresponding author: Sri Harsha Jalli, Vignan Institute of pharmaceutical sciences, Deshmukhi, Nalgonda, Tel: 9703366353; E-mail: jalliharsha@gmail.com

Received April 08, 2015; Accepted May 11, 2015; Published May 18, 2015

Citation: Sriharsha J, Srinivasa Murthy M, Bharat Kumar D, Sravan K, Shiva kumar P, et al. (2015) Method Development and Validation for Simultaneous Estimation of Dexlansoprazole and Meloxicam by Rp-Hplc. Pharm Anal Acta 6: 370. doi:10.4172/21532435.1000370

Copyright: (c) 2015 Sriharsha J, et al. This is an open-access article distributed under the terms of the Creative Commons Attribution License, which permits unrestricted use, distribution, and reproduction in any medium, provided the original author and source are credited. 


\section{Method Development for HPLC}

Trail 1

Mobile Phase: Degassed Methanol: Water in the ratio of 90:10V/V

Observation: No proper shape of the peaks and extra peaks observed.

Trail 2

Mobile Phase: Degassed Methanol: Water in the ratio of 80:20V/V

Observation: Asymmetric peaks were observed.

Trail 3

Mobile Phase: Degassed Methanol: Water in the ratio of 40:60V/V

Observation: Asymmetric peaks were observed and efficiency of separation is not good.

Trail 4

Mobile Phase: Degassed Methanol: Water in the ratio of 50:50V/V

Observation: Peak fronting is seen in both the peaks.

Trail 5

Mobile Phase: Acetonitrile: Water in the ratio of 50:50V/V

Observation: Peak splitting is seen and peak tailing is seen.

Trail 6

Mobile Phase: Methanol: Acetonitrile in the ratio of $90: 10 \mathrm{~V} / \mathrm{V}$

Observation: Sharp peaks are not observed.

Trail 7

Mobile Phase: Methanol: Acetonitrile in the ratio of 80:20V/V

Observation: Peak tailing is seen and no sharp peaks are observed.

Trail 8:

Mobile Phase: Methanol: Acetonitrile in the ratio of 70:30V/V

Observation: Good resolution is seen but sharp peaks are not obtained.

Trail 9: Optimized Method

Mobile Phase:

Observation: Good resolution and sharp peaks with good elution are observed (Figure 1) (Table 1).

\section{Method Validation}

Analytical Method Validation Parameters

This Validation describes the procedure by HPLC as per ICH Guidelines (Q2B). The method validation parameters include:

Specificity

Linearity

Accuracy

Range

Precision

Intermediate precision (ruggedness)

Method precision

Robustness

System suitability

\section{Results and Discussion}

The chromatographic method development for the estimation of Meloxicam and Dexlansoprazole were optimized by several trials for various parameters as different column, flow rate and mobile phase, finally the following chromatographic method was selected for the quantification of Meloxicam and Dexlansoprazole by RP-HPLC [1416].

\section{Validation Report}

\section{Specificity}

The method shows excellent specificity with Meloxicam and Dexlansoprazole eluting at retention of 2.95 minutes and 4.19 minutes respectively. No interference was observed with mobile phase [17-19].

\section{Linearity}

The linearity study was performed and the correlation coefficient of Meloxicam and Dexlansoprazole were found to be 0.9997 and 0.9995 respectively (NMT 0.999).

\section{Accuracy}

The accuracy study was performed for $\%$ recovery. The $\%$ recovery was found to be $99.7 \%$ to $100.6 \%$ for Meloxicam. (NLT 98\% and NMT $102 \%)$.

The accuracy study was performed for $\%$ recovery. The $\%$ recovery

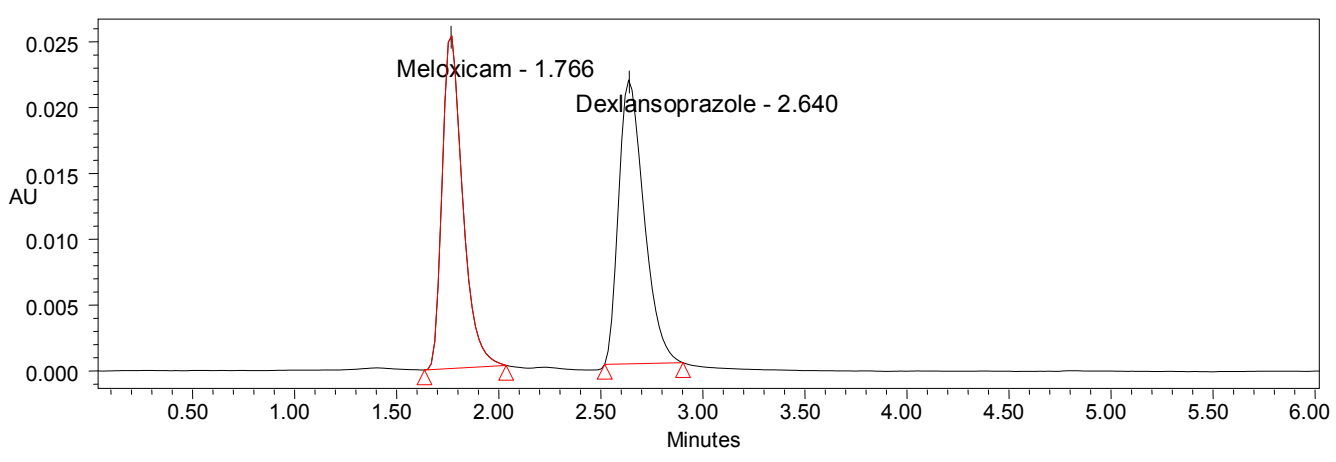

Figure 1: Optimized method-Methanol: Acetonitrile in the ratio of 60:40V/V. 
Citation: Sriharsha J, Srinivasa Murthy M, Bharat Kumar D, Sravan K, Shiva kumar P, et al. (2015)Method Development and Validation for Simultaneous Estimation of Dexlansoprazole and Meloxicam by Rp-Hplc. Pharm Anal Acta 6: 370. doi:10.4172/21532435.1000370

Page 3 of 3

\begin{tabular}{|c|c|c|c|c|c|c|c|c|}
\hline & Name & Retention Time & Area & $\%$ Area & Height & USP Resolution & USP Tailing & USP Plate Count \\
\hline 1 & Meloxicam & 1.766 & 177126 & 48.75 & 25253 & & 1.389748 & 1522.681250 \\
\hline 2 & Dexlansoprazole & 2.640 & 186204 & 51.25 & 21571 & 4.116883 & 1.403226 & 2052.683951 \\
\hline
\end{tabular}

Table 1: Trail 9 Methanol: Acetonitrile in the ratio of 70:30V/N.

was found to be $99.9 \%$ to $100.4 \%$ for Dexlansoprazole. (NLT $98 \%$ and NMT 102\%).

\section{Summary and Conclusion}

The analytical method was developed by studying different parameters. Isobistic point of wavelength for both the drugs was set at $248 \mathrm{~nm}$ and the peaks purity was excellent. Injection volume was selected to be $20 \mu \mathrm{l}$ which gave a good peak area. The column used for study was Hypersil C18 BDS, chosen good peak shape. Ambient temperature was found to be suitable for the nature of drug solution. The flow rate was fixed at $1.0 \mathrm{ml} / \mathrm{min}$ because of good peak area, satisfactory retention time and good resolution. Different ratios of mobile phase with ratio of 60:40 methanol: acetonitrile was fixed due to good symmetrical peaks and for good resolution. So this mobile phase was used for the proposed study.The result obtained in this study demonstrated that the HPLC method described is specific, accurate, precise, linear, rugged, robust and stability indicating for the determination of assay of Meloxicam and Dexlansoprazole. Therefore, the method is suitable for intended uses.

\section{References}

1. Ahuja S (2006) In: Impurities evaluation of pharmaceuticals. Marcel Dekker Inc New York 1-10.

2. British pharmacopoeia (2007) CD-ROM version.

3. Nemutlu E, Kır S (2004) Validated Determination of Meloxicam in Tablets by Using UV Spectrophotometry. Hacettepe University Journal of The Faculty of Pharmacy 24: 13-24.

4. Nemutlu E, Kir S (2003) Method development and validation for the analysis of meloxicam in tablets by CZE. J Pharm Biomed Anal 31: 393-400.

5. Nageswara Rao R, Meena S, Raghuram Rao A (2005) An overview of the recent developments in analytical methodologies for determination of COX2 inhibitors in bulk drugs, pharmaceuticals and biological matrices. J Pharm Biomed Anal 39: 349-363.

6. Zawilla NH, Abdul-Azim Mohammad M, El kousy NM, El-Moghazy Aly SM (2003) Determination of meloxicam in bulk and pharmaceutical formulations. J Pharm Biomed Anal 32: 1135-1144.
7. Nemutlu E, Sayn F, Bac NE, Kr S (2007) A Validated Hplc Method for the Determination of Meloxicam in Pharmaceutical Preparations. Hacettepe University Journal of the Faculty of Pharmacy 27: 107-118.

8. Vignaduzzo SE, Castellano PM, Kaufman TS (2008) Method development and validation for the simultaneous determination of meloxicam and pridino mesylate using RP-HPLC and its application in drug formulations. J Pharm Biomed Anal 46: 219-225.

9. Bae JW, Kim MJ, Jang CG, Lee SY (2007) Determination of meloxicam in human plasma using a HPLC method with UV detection and its application to a pharmacokinetic study. J Chromatogr B Analyt Technol Biomed Life Sci 859: 69-73.

10. Dasandi B, Shivaprakash, Saroj H, Bhat KM (2002) LC determination and pharmacokinetics of meloxicam. J Pharm Biomed Anal 28: 999-1004.

11. Velpandian T, Jaiswal J, Bhardwaj RK, Gupta SK (2000) Development and validation of a new high-performance liquid chromatographic estimation method of meloxicam in biological samples. J Chromatogr B Biomed Sci App 738: $431-436$.

12. Alvarenga L, Ferreira D, Altekruse D, Menezes JC, Lochmann D (2008) Tablet identification using near-infrared spectroscopy (NIRS) for pharmaceutical quality control. J Pharm Biomed Anal 48: 62-69.

13. Emirhannemulla S (2004) Validated Determination of meloxicam in tablet by using uv spectrophotometry. Journal Of The Faculty Of Pharmacy 24 :13-24

14. Farzana SB, Pradeep RV (2009) A Stability indicating HPLC method for the determination of meloxicam in bulk and commercial formulation. Trop J Pharm Res 8: 257-64

15. Gasilova NV, Eramin SA (2006) Determination of chloramphenicol in milk by a fluorosence polarization immuno assay. Flouroscence spectroscopy 4: 449-96

16. Ramos M, Muñoz P, Aranda A, Rodriguez I, Diaz R, et al. (2003) Determination of chloramphenicol residues in shrimps by liquid chromatography-mass spectrometry. J Chromatogr B Analyt Technol Biomed Life Sci 791: 31-38.

17. Boyd B, Björk H, Billing J, Shimelis O, Axelsson S, et al. (2007) Development of an improved method for trace analysis of chloramphenicol using molecularly imprinted polymers. J Chromatogr A 1174: 63-71.

18. Resnick GL, Corbin D, Sandberg DH (1966) Determination of serum chloramphenicol utilizing gas--liquid chromatography and electron capture spectrometry. Anal Chem 38: 582-585

19. Morelli B (1987) Spectrophotometric assay for chloramphenicol and some derivatives in the pure form and in formulations. J Pharm Biomed Anal 5: 577-583. 